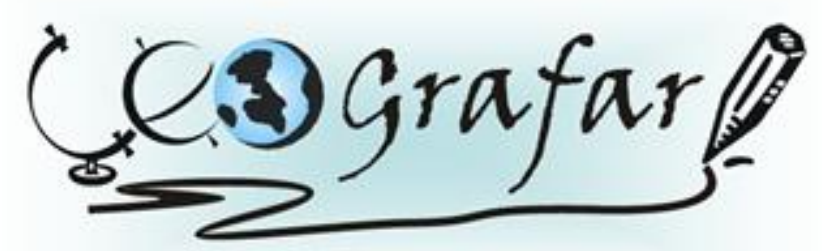

Revista Eletrônica do Programa de Pós-Graduação em Geografla - UFPR

\title{
DA PAISAGEM SONORA À PRODUÇÃO MUSICAL: Contribuições geográficas para 0 estudo da paisagem
}

\section{MARCOS ALBERTO TORRES}

Resumo: Diferentes definições do conceito de paisagem vêm sendo discutidas e empregadas na Geografia desde seu surgimento enquanto ciência. No entanto, ainda que alguns admitam a(s) dinâmica(s) existente(s) na paisagem, poucos são os que a encarem além do visual. Com isso, minimizam as possibilidades de ensino acerca da realidade, dificultando o re-conhecimento dos elementos constituintes da paisagem e de sua dinâmica cultural. $O$ presente trabalho relata a experiência da oficina "Percussivos e Eletrônicos: a paisagem sonora e a música", ofertada no III Festival de Arte da Rede Estudantil do Paraná, no município de Francisco Beltrão em abril de 2006, na qual participaram jovens de 11 a 18 anos matriculados na rede pública de ensino. Pretende ainda contribuir para o pensamento geográfico, apontando caminhos dentro da geografia humana e cultural, apoiados na fenomenologia da percepção. Prática e produção musical foram propostas utilizadas na oficina para se pensar a paisagem sonora como elemento produzido pela cultura, e influenciador na sua "construção". Através da paisagem sonora explorou-se a sensibilização auditiva e as reflexões acerca de sua influência na cultura, e vice-versa. A produção musical dialogou com instrumentos tradicionais (percussão), modernos (elétricos) e contemporâneos (eletrônicos), trabalhando letra, melodia e harmonia. Dessa forma, a metodologia consistiu em discussões teóricas e exercícios práticos, resultando em músicas identitárias, com letras que retratavam as realidades vividas pelos jovens, e ritmos marcados pela influência da cultura gaúcha presente naquela região.

Palavras-chave: Paisagem sonora, percepção, geografia, música.

\begin{abstract}
Different definitions about landscape concept have been discussed and employed in geography, since it was considered a science. Although some admit that there is(are) dynamic(s) in landscape, few scholars think it is beyond the visual. Thus, they minimize the possibilities of teaching about the reality, making it difficult the re-understanding of the components of the landscape and its cultural dynamics. This paper reports the experience of the workshop "percussive and Electronics: a soundscape and music," offered in the III Festival of Art Student of Paraná, in the city of Francitsco Beltrão, in April 2006. The contestants were students from 11 to 18 years old enrolled in public school system. This work also aims to contribute to the geographic thought, pointing paths within human and cultural geography, based on the phenomenology of perception. Practice and music production were proposed to be used in such workshop, in order to consider the soundscape as an element produced by culture, and influenced in its "construction". Through the soundscape the hearing awareness was explored, as well as reflections about their influence on culture and vice versa. The musical production interacted to traditional instruments (percussion), modern ones (electric) and contemporary ones (electronic), working with lyrics, melody and harmony. Therefore, the methodology consisted of theoretical discussions and practical exercises, resulting in identity songs, with lyrics that portrayed the realities experienced by young people, and rhythms marked by the influence of the culture of that region.
\end{abstract}

Keywords: soundscape, perception, geography, music.

\footnotetext{
${ }^{1}$ Mestre em Geografia, Universidade Federal do Paraná. torresmarcos@hotmail.com
} 


\section{INTRODUÇÃO}

Caminhar por uma cidade implica, diretamente, caminhar em meio a um universo de sons: veículos automotores, os passos e as conversas das pessoas, propagandas comerciais, aparelhos eletro-eletrônicos, manifestações religiosas, construção civil, entre outros. Em meio a essa infinidade de sons, o homem segue compondo o cenário sonoro. Os sons que ocorrem em um determinado lugar, o que inclui também a música, compõem a paisagem sonora, que, por sua vez, integra a paisagem e reflete a sua cultura.

Segundo Berque (2004, p. 86), a paisagem é plurimodal (passiva-ativapotencial etc.) como é plurimodal o sujeito para o qual a paisagem existe. Para ele, paisagem e sujeito são co-integrados em um conjunto unitário, que se autoproduz e se auto-reproduz. Nesse sentido, fica claro que a análise da paisagem não deve valer-se apenas do aspecto visual, pois a visão não é suficiente para captar e explicar todos os elementos físicos e simbólicos presentes na paisagem.

De fato, o que está em causa não é somente a visão, mas todos os sentidos; não somente a percepção, mas todos os modos de relação do indivíduo com o mundo; enfim, não é somente o indivíduo, mas tudo aquilo pelo qual a sociedade o condiciona e o supera, isto é, ela situa os indivíduos no seio de uma cultura, dando com isso um sentido à sua relação com o mundo (sentido que, naturalmente, nunca é exatamente o mesmo para cada indivíduo). (BERQUE, 2004, p. 87)

Diante disso, os demais elementos de uma paisagem ganham foco: os sons, os cheiros, as formas e os movimentos, assim como os símbolos e significados presentes na paisagem. Todo som (falas, ruídos, músicas, etc.) e todo cheiro (perfumes, plantas, esgotos, etc.) têm uma origem que está diretamente relacionada ao lugar. Nossas percepções e nossos olhares perpassam nossas experiências e vivências em diferentes tipos de espaços.

A música, enquanto elemento que integra a paisagem sonora, pode retratar o lugar onde foi produzida, pelas sonoridades peculiares dos instrumentos musicais, ou ainda pelas falas e sotaques nela empregada, diretamente relacionadas à cultura e à história do seu povo. 
O presente artigo traz à discussão o conceito de paisagem, tendo como foco a paisagem sonora, e busca apontar possibilidades aos estudos geográficos, de modo a ir além da forma visual da paisagem na busca da compreensão dos lugares. Fará isso por meio do relato da experiência da oficina "Percussivos e Eletrônicos: a paisagem sonora e a música", ofertada no III Festival de Arte da Rede Estudantil do Paraná, no município de Francisco Beltrão em abril de 2006, na qual participaram vinte e cinco jovens de 11 a 18 anos, dentre os quais apenas cinco tinham instrução musical. Todos os participantes eram alunos da rede pública estadual de ensino do estado do Paraná. A oficina objetivou a sensibilização e o incentivo à criação musical (letra, ritmo, melodia e harmonia), o registro dos trabalhos em meio digital e a discussão acerca das possibilidades de divulgação e difusão dos trabalhos musicais. Com isso, a prática e a produção musical foram utilizadas para a reflexão sobre a relação estabelecida entre a paisagem sonora e a cultura. Através da paisagem sonora explorou-se a sensibilização auditiva e as reflexões acerca de sua influência na cultura, e vice-versa.

\section{A LEITURA DAS PAISAGENS}

Enquanto apreensão do real em um determinado momento, a paisagem é portadora de inúmeros elementos e significados. A paisagem não é apenas visual e estática, mas dinâmica e carregada de barulhos, cheiros, gostos e valores sociais e culturais, que devem ser considerados no seu estudo. Para Almeida, "a paisagem é uma complexidade multiforme de realidades, de valores, de gestos e de vividos coexistentes" (ALMEIDA, 2003, p. 86). Ao mesmo tempo em que apresenta elementos da(s) vida(s) que a habita, é refletida por cada vida que nela há. Diante disso, o estudo da paisagem deve considerar tais elementos, percebidos e vividos pelos indivíduos.

Segundo Merleau-Ponty (1999, p. 63), "perceber no sentido pleno da palavra, (...) não é julgar, é apreender um sentido imanente ao sensível antes de qualquer juízo". O sentir, por sua vez, é a experiência íntima com o lugar, objeto ou fenômeno, de modo que tato, audição, visão, olfato e paladar interajam mutuamente na percepção individual. Perceber a paisagem traz sempre as relações do indivíduo 
com um mundo novo ou renovado, que surge a cada experiência, o que implica em reconhecer-se, que para Claval "(...) supõe uma apropriação do espaço pelo sentido. É plenamente uma experiência individual, mesmo se os saberes coletivos e a aculturação também contribuem". (CLAVAL, 2001, p. 194).

Perceber a paisagem é sentir-la, fazendo parte dela e relacionando-a com seu mundo. Nisto, a paisagem torna-se subjetiva, tornando-se única, na medida em que o coletivo destaca suas similitudes, formando uma unidade no imaginário social. Cosgrove (1998, p. 99) especifica três implicações do conceito de paisagem: "(1) um foco nas formas visíveis de nosso mundo, sua composição e estrutura espacial; (2) unidade, coerência e ordem ou concepção racional do meio ambiente; (3) a idéia de intervenção humana e controle das forças que modelam e remodelam nosso mundo". Acrescenta-se à idéia de Cosgrove o fato de que todas as formas presentes na paisagem devem ser levadas em consideração, tanto as visíveis, quanto as percebidas por meio dos outros sentidos humanos. A paisagem relaciona natureza e sociedade, ou o meio e o homem, ao passo que este toma consciência do esquema da natureza que o envolve.

A paisagem está carregada de significados. Templos religiosos, prédios comerciais, lanchonetes, escolas, teatros, cinemas, ruas, etc., se tornam territórios, locais de passagens ou, ainda, apenas marcos visuais; mas para uma determinada população pode representar valores, permeados pela cultura. Para o estudo da paisagem, o campo de pesquisa vai além do visual. A paisagem é um complexo de cultura e formas.

[...] a paisagem é, ao mesmo tempo, ancorada no solo, modelada pelas transformações naturais e pelo trabalho do homem e, acima de tudo, objeto de um sistema de valores construído historicamente e apreendido diferentemente, no tempo e no espaço, pela percepção humana. (LUCHIARI, 2001, p. 19)

Dos cinco sentidos existentes nos seres humanos, o tato é o mais pessoal deles. As experiências a partir do corpo revelam as primeiras relações com o espaço. "O tato é a experiência direta da resistência, a experiência direta do mundo como um sistema de resistência e de pressões que nos persuadem da existência de uma realidade independente de nossa imaginação". (TUAN, 1980, p. 09). 
O ouvir, nas palavras de Azevedo, (1984, p. 03) "indiscutivelmente, é uma das melhores maneiras de nos apercebermos do que se passa ao redor. Nada mais simples e fácil do que o meio de comunicação pela fala. Outros sons, como campainhas, sirenes, buzinas, nos traduzem também alguma informação."

Os sons que ocorrem nos lugares compõem suas paisagens sonoras, que são, por sua vez, integrantes de suas paisagens. São ainda portadores de valores culturais, como, por exemplo, o toque do sino de uma igreja, as diferentes línguas e sotaques, o som do trânsito de uma metrópole, etc.

Contudo, há no estudo da paisagem na Geografia uma tendência em se priorizar o aspecto visual. Afirmar essa prioridade seria um erro, a começar pela reflexão acerca da capacidade organizacional do espaço que um cego possui. "Podemos estabelecer a priori que todos os sentidos são espaciais, e a questão de saber qual é o sentido que nos dá o espaço deve ser considerada como ininteligível se refletimos no que é um sentido" (MERLEAU-PONTY, 1999, p. 294).

Para Schafer:

A audição e o tato se encontram no ponto em que as mais baixas freqüências de sons audíveis passam a vibrações tácteis (cerca de 20 hertz). A audição é um modo de tocar a distância, e a intimidade do primeiro sentido funde-se à sociabilidade cada vez que as pessoas se reúnem para ouvir algo especial. (SCHAFER, 2001, p. 29)

A paisagem apresenta-se para o estudo geográfico como elemento multifacetado, combinando formas e cultura, significados e valores. "Neste sentido, quem sabe perceber uma paisagem, consegue entender seu valor, perceber a importância da mesma em sua vida, criar vínculo afetivo com a mesma e, conseqüentemente, defender a sua perpetuação" (SCHIER, 2004, p. 19).

As paisagens sonoras, apesar de exploradas por musicólogos, antropólogos e etnomusicólogos, apresentam-se à Geografia como importante campo de estudo. Assim como a olfativa, a paisagem sonora é marcante para a lembrança de um lugar, concordando com Stanley Waterman (2006, p. 01), que afirma que os sentidos da audição e do olfato são capazes de evocar memórias e imagens mais poderosas 
do que as coisas que vemos, e seus usos seletivos permitem a produção de imagens mais robustas. Para este autor, os olhos fazem a varredura e captam o cenário mais amplo rapidamente, mas os sentidos da audição e do olfato reagem mais lentamente e talvez mais profundamente.

As paisagens sonoras concedem identidades aos lugares, e agem direta e constantemente em seus moradores na contribuição à perpetuação das falas e sotaques, dos gostos musicais, e na evocação de paisagens do passado, o que reforça valores existentes em cada indivíduo, que pode contribuir para sua fixação em lugares distintos, e à criação do sentimento de pertencimento a eles, pelo fato de apresentarem sonoridades que concedem familiaridade na paisagem.

\section{A PAISAGEM SONORA E A MÚSICA}

O mundo contemporâneo presencia o surgimento e a proliferação de uma infinidade de novos sons que diferem em qualidade e intensidade. Esses novos sons fundem-se aos historicamente já existentes, superpovoando o meio. Segundo Schafer,

[...] quando haviam poucas pessoas e elas levavam uma existência pastoril, os sons da natureza pareciam predominar: ventos, água, aves, animais, trovões. As pessoas usavam seus ouvidos para decifrar os presságios sonoros da natureza. Mais tarde, na paisagem urbana, as vozes das pessoas, seu riso e o som de suas atividades artesanais pareceram assumir o primeiro plano. Ainda mais tarde, depois da Revolução Industrial, os sons mecânicos abafaram tanto os sons humanos quanto os naturais, com seu onipresente zunido. (SCHAFER, 1991, p. 128)

Em diferentes lugares, a paisagem sonora apresenta-se com inúmeras informações, sejam elas urbanas e tecnificadas - como nos grandes centros urbanos -, ou de um ambiente natural ou próximo disso - como numa ilha distante, ou em uma fazenda numa área rural. Entretanto, a paisagem sonora é pouco percebida pelos seres humanos, assim como as transformações que nela ocorrem, conforme assinalado por Tuan, quando afirmou que o mundo é percebido pelo ser humano simultaneamente através de todos os sentidos, sendo imensa a informação 
potencialmente disponível, mas que, no entanto, no dia a dia do homem, é utilizada somente uma pequena porção do seu poder inato para experienciar (TUAN, 1980, p. 12).

A paisagem sonora é cultural, pois reflete a identidade de um lugar e de seus habitantes. É na paisagem sonora que encontramos subsídios para pensar na perpetuação das diferentes falas e sotaques dos grupos sociais, e no estabelecimento da comunicação entre seus integrantes.

Do mesmo modo que a fala, a música integra a paisagem sonora, e, enquanto expressão artística, também compõe o universo simbólico de um povo. Deve ser estudada, sobretudo, no aspecto subjetivo que esta possui, pois, conforme alerta Cassirer, a arte "não é nem uma imitação de coisas físicas, nem um simples transbordar de sentimentos poderosos. É uma interpretação da realidade - não através de conceitos, mas de intuições; por meio não do pensamento, mas das formas sensuais" (CASSIRER, 1994, p. 240). No campo musical essa afirmativa encontra a subjetividade presente em quem faz música e também no seu ouvinte. Ao passo que uma coletividade expressa um modo próprio de fazer e/ou apreciar a produção musical, ganha-se evidência o aspecto cultural da música, que é onde as subjetividades encontram suas similitudes.

A música, entendida como "o som culturalmente organizado pelo homem" (Blacking, 1973 apud PINTO, 2001, p. 224), manifesta-se na paisagem sonora e nela encontra as bases sonoras para seu surgimento e perpetuação. A cultura, a paisagem e o lugar concedem as bases para a construção musical, que em diferentes contextos assimilou os sons presentes no espaço, chegando, em certos casos, a alterar a forma de pensar e fazer música, conforme apontou Claire Gui, ao destacar:

As primeiras composições da música descritiva, no século $\mathrm{XIX}$, a integração do 'ruído' nas composições musicais, a partir dos anos 1920, e então a procura de uma estética do ouvir a paisagem sonora e a criação de músicas espaciais na década de 1960 (por John Cage, Pierre Schaffer e Murray Schafer) contribuiu para várias transformações no fazer musical, porque o espaço, o ambiente e o 
território se tornaram elementos inerentes no processo de compor música $^{2}$ (GUI, 2007, p. 03).

A música retrata a cultura e a memória do povo. É uma coleção de sons concebidos e produzidos por sucessivas operações de pessoas que ouvem bem (SCHAFER, 1991, p. 187), que quando executada, integra-se à paisagem sonora tornando-se um de seus elementos. Ao referir-se ao trabalho do antropólogo Alan $P$. Merrian $^{3}$, Pinto afirma que "o fazer musical é um comportamento aprendido, através do qual sons são organizados, possibilitando uma forma simbólica de comunicação na inter-relação entre indivíduo e grupo". (PINTO, 2001, p. 224). Compreende-se, portanto, que a música é um elemento cultural, assim como é um elemento integrante da paisagem sonora, e é por ela transformada. Os sons presentes na paisagem sonora, sejam eles de origem natural ou produzidos pelos seres humanos nas mais variadas formas, estão inteiramente ligados à memória e à cultura.

À Geografia, o estudo da cultura e da paisagem pautado na paisagem sonora, possível por meio de uma abordagem humanista-cultural, traz à luz as preocupações com a compreensão de como o indivíduo e o coletivo constroem e concebem 0 espaço. A paisagem sonora é, dessa forma, apreendida e ao mesmo tempo transformada, diferentemente em cada localidade, em cada grupo, em cada cultura.

A música de um lugar pode oferecer importantes subsídios ao estudo geográfico, visto que ela, segundo Carney (2007, p. 145), tanto reflete quanto influencia as imagens que as pessoas possuem de lugares e a forma como essas imagens mudaram significativamente as atitudes das pessoas para com lugares. Para este autor "esse é outro passo para se compreender a 'geografia da mente"'. Carney ainda afirma que

\footnotetext{
${ }^{2}$ Tradução livre. No original: "Les premières compositions de musique descriptive, au 19ème siècle, l'intégration $d u$ "bruit" dans les compositions musicales, à partir des années 1920, puis les revendications pour une écoute esthétique du paysage sonore et la création de musique spatiale dans les années 1960 (par John Cage, Pierre Schaeffer ou Murray Schaffer notamment) ont contribué à plusieurs transformations du fait musical, puisque l'espace, l'environnement et le territoire sont devenus des éléments inhérents des processus de composition musicale."

${ }^{3}$ A referência é ao livro The Anthropology of Music, publicado em 1964 pela Northwestern University Press, considerado decisivo para a abordagem antropológica nos estudos da etnomusicologia.
} 
No estudo da música como um meio, devem ser levados em consideração o mensageiro e o mecanismo desse meio, isto é, os compositores, arranjadores, músicos, instrumentos, engenheiros de som, equipamento de gravação e estúdios de gravação. Por exemplo, os antecedentes culturais do compositor, suas percepções e conhecimento do lugar, bem como suas intenções (propósito, fundamentação lógica, objetivos, inclusão ou exclusão de determinados aspectos do lugar e o público ouvinte), podem influenciar a natureza do lugar representado. (CARNEY, 2007, p.144)

O estudo da música deve levar em consideração o lugar onde ela é produzida e tocada, com seus valores sociais e culturais. Pensar o lugar remete a pensar em sua localização e em sua(s) história(s), assim como nas paisagens que este comporta. O lugar comporta objetos e valores através dos símbolos, signos e significados. É no lugar que as relações sociais ocorrem, e através delas os valores são compartilhados. A topofilia (TUAN, 1980) - elo afetivo entre a pessoa e o lugar está ligada a estes valores quando surge a sensação de pertencimento ao lugar.

\section{DA MÚSICA À BUSCA DA COMPREENSÃO DA CULTURA}

Explorar a música dos jovens da região de Francisco Beltrão ${ }^{4}$, no sudoeste do estado do Paraná, foi o desafio para entender parte da cultura da região e do modo de vida dos que a habitam. Para isso foram estipulados os seguintes objetivos na oficina ofertada:

- Sensibilizar musicalmente através da paisagem sonora, possuidora de sons naturais e artificiais;

- Debater acerca dos diferentes recursos eletrônicos presentes na música atual, partindo para a criação musical utilizando instrumentos de percussão em conjunto com recursos e efeitos sonoros eletrônicos criados a partir do computador, possibilitando a inserção de outros instrumentos que venham a ser trazidos pelos participantes da oficina;

- Registro em meio digital (CD), tendo a possibilidade de difusão por meio da internet discutida durante a oficina.

${ }^{4}$ Participaram da oficina jovens moradores do município de Francisco Beltrão e dos municípios vizinhos, como Itapejara D'Oeste, Verê, Marmeleiro, Enéas Marques e Dois Vizinhos. 
A oficina aconteceu em três momentos, distribuídos em quatro dias. Cada momento reservou discussões teóricas e atividades práticas, estas consistindo de exercícios de percepção e prática musical. Os temas explorados em cada um dos momentos foram:

1ำ momento

- Abordagens sobre paisagem, cultura e música: conceitos e possibilidades;

- A paisagem sonora e o tempo;

- Exercícios de clariaudiência ${ }^{5}$.

$2^{\circ}$ momento

- Inclusão Digital: A revolução tecnocientífica e o uso da tecnologia nas diferentes áreas da vida;

- A percussão na música brasileira;

- A cultura brasileira, seus elementos atuais e sua música.

3ำ momento

- Música eletrônica: discutindo e introduzindo recursos eletrônicos na música brasileira;

- Técnicas de percussão: ritmo, criação e improvisação;

- Técnicas em softwares de produção musical;

- Criação, registro e difusão musical.

Em cada momento da oficina foram debatidos os conceitos de música e sua relação com a cultura, e explorados os sons da natureza e as possibilidades de apropriação deles para a produção sonora.

A percepção auditiva foi trabalhada através dos sons da paisagem sonora local - natural e artificial, e também da exploração dos instrumentos de percussão, no intuito de buscar primeiramente uma educação rítmica, para, posteriormente, buscar

${ }^{5}$ Estes exercícios consistem, metaforicamente, numa "limpeza do ouvir", explorando a sensibilidade da audição como receptora de informações. 
individualmente os ritmos produzidos por cada participante, e, em seguida, encontrar consensos rítmicos no grupo.

Exercícios de movimento corporal, como fonte de recursos sonoros (percussão corporal) foram executados, objetivando outras possibilidades na criação de sons e demais elementos inseridos na música e na natureza.

Em grupos, os alunos compuseram letras com temas livres, e como resultado obteve-se retratos dos sonhos, das alegrias e do cotidiano jovem. Em seguida, criaram melodias para as mesmas, baseando-se, primeiramente, em um ritmo por eles criado a partir dos instrumentos de percussão.

Os conceitos de música eletrônica e equipamentos eletrônicos foram discutidos e, a partir do terceiro dia, os microcomputadores foram utilizados, com softwares ${ }^{6}$ específicos, para as gravações e edições das músicas. O último dia foi destinado às finalizações das criações e registros das mesmas em meio digital (CD), e discutidas as possibilidades de difusão pela internet e rádios locais.

Como resultado final, três canções foram concebidas pelos participantes. $O$ que chamou a atenção foi o fato de, ao congregar jovens com diferentes gostos musicais, mas que viviam numa mesma região, obteve-se como resultado a composição de músicas que retratavam em suas letras o modo de vida do jovem contemporâneo, e em suas células rítmicas elementos que remetiam à música gauchesca. A pergunta que surgiu após o resultado final da oficina, e que está diretamente relacionada às questões da paisagem sonora e, portanto, geográficas, foi: como explicar a "batida gaúcha" presente nas músicas, visto que os jovens tinham preferências musicais diversas, indo do pop-rock ao RAP, do heavy-metal ao dance?

Numa tentativa de explicar tal fato, pode-se remeter, primeiramente, ao conceito de inconsciente coletivo de Carl Gustav Jung (2000, p. 53, 54). Para esse autor o inconsciente coletivo, diferente do inconsciente pessoal, não deve sua existência à experiência pessoal. Enquanto o inconsciente pessoal é constituído essencialmente de conteúdos que já foram conscientes e, no entanto desapareceram da consciência por terem sido esquecidos ou reprimidos, os

\footnotetext{
${ }^{6}$ Os softwares utilizados foram o Sony Vegas e o Sony Acid Pro.
} 
conteúdos do inconsciente coletivo nunca estiveram na consciência e, portanto não foram adquiridos individualmente, mas devem sua existência apenas à hereditariedade. Enquanto o inconsciente pessoal consiste em sua maior parte de complexos, o conteúdo do inconsciente coletivo é constituído essencialmente de arquétipos, conceituado por ele como a indicação da "existência de determinadas formas na psique, que estão presentes em todo tempo e em todo lugar".

A formação do inconsciente coletivo depende do grupo. Ele não se desenvolve individualmente, mas é herdado, consistindo em formas preexistentes - arquétipos que tornar-se-ão conscientes posteriormente, conferindo uma forma definida aos conteúdos da consciência. (JUNG, 2000, p. 55). Pode-se aqui atribuir o conceito de arquétipos às estruturas rítmicas aplicadas nas músicas resultantes da oficina. As seqüências de sons aplicadas, como ritmo escolhido pelos grupos, são "formas" sonoras, marcadas e presentes na mente de cada um dos jovens. Por mais que houvesse diferentes gostos musicais declarados, ao desenvolverem suas próprias músicas, as células rítmicas mais fortes em suas mentes ainda eram a de suas origens: a música gaúcha. Maurice Halbwachs, em seu artigo "A memória coletiva entre os músicos", de 1939, questiona a memória de um não-músico ao guardar apenas uma seqüência de sons e não outras, e conclui que é "porque imediatamente apreendemos seu ritmo. Não somente porque é simples, mas porque nosso ouvido nele encontra movimentos, uma velocidade, um balanceio que já conhece e que the é quase familiar". (HALBWACHS, 2006, p. 208)

Em Francisco Beltrão e nos municípios vizinhos, grande parte da população é originária do Rio Grande do Sul. Marcos visuais, como o monumento da Cuia na Praça Eduardo Virmond Suplicy, no centro da cidade de Francisco Beltrão, remete à cultura presente na região. Entretanto, esta não está apenas nos monumentos e nas rodas de chimarrão, comuns entre seus habitantes, mas também na sonoridade da fala e, por sua vez, na paisagem sonora. As músicas produzidas por seus moradores reproduzem estes valores. Os ritmos - que no caso estudado apresentaram a influência da cultura gaúcha - criados pelos jovens participantes da oficina, nos quais pautaram suas músicas, são também produtos culturais, pois como diz Halbwachs acerca do ritmo: 
Ele não existe na natureza? Não imaginamos que um homem isolado possa descobrir sozinho no espaço sonoro essas divisões rítmicas? Se algum fenômeno natural insinuasse 0 ritmo não haveria necessidade de recebe-lo dos outros homens. Os ruídos que nos chegam da natureza, e só dela, não se sucedem segundo uma medida ou uma cadência qualquer. O ritmo é um produto da vida em sociedade. Sozinho, 0 indivíduo não poderia inventa-lo. (HALBWACHS, 2006, p. 207)

As músicas que foram compostas na oficina relatada apresentaram marcas do lugar e da cultura. Além das marcas, apresentou-se como fruto desses elementos, mostrando assim a interconectividade entre os mesmos. Os exercícios de escuta e de leitura da paisagem, com ênfase na paisagem sonora, podem ter contribuído para uma composição musical com identidade sonora.

\section{ALGUMAS CONSIDERAÇÕES...}

A paisagem sonora compreendida como todos os sons de um ambiente (SCHAFER, 2001), deve considerar também a música tocada e ouvida nos diferentes lugares. Entendida como um evento (ONG apud POCOCK, 1989, p. 193), deve ser analisada dentro de um recorte de tempo maior que o destinado à paisagem visual, e está totalmente atrelada à memória. A música, dessa forma, integra a paisagem sonora, e é ainda um registro dos sons de uma época (SCHAFER, 2001, p.151).

Wisnik (1989, p. 33) afirma que a música organiza sons que o mundo oferece, e para Blackin (apud PINTO, 2001, p. 224), a música é entendida como o som culturalmente organizado pelo homem. Segundo Levintin, "[...] o estudo da música tem uma importância central para a ciência cognitiva porque a música está entre as atividades humanas mais complexas, envolvendo percepção, memória, tempo, agrupamento de objetos, atenção e (no caso da performance) perícia e uma coordenação complexa da atividade motora" (LEVINTIN, p. 44). Desse modo, a música apresentou-se sob o ritmo "gauchesco" no presente relato, como importante elemento a ser considerado no levantamento das percepções e vivências dos entrevistados, assim como na busca da compreensão das construções espaciais tidas por eles. 
Diante do exposto, a preocupação central do presente artigo foi apontar algumas relações entre música, paisagem sonora, paisagem e cultura, e relatar uma forma alternativa, por meio da construção musical, como possibilidades que se completam na busca de explicações acerca da construção do espaço. Trabalhos geográficos que tenham como proposta uma abordagem cultural devem atentar para os diferentes olhares dos indivíduos, buscando similitudes mas respeitando as individualidades.

\section{REFERÊNCIAS}

ALMEIDA, M. G. de. Em busca do poético do sertão. In: ALMEIDA, M. G. de, RATTS, A. (orgs.). GEOGRAFIA: leituras culturais. Goiânia: Editora Alternativa, 2003.

AZEVEDO, A. V. Avaliação e controle do ruído industrial. Rio de Janeiro: CNI Departamento de Assistência à Média e Pequena Indústria, 1984.

BERQUE, A. Paisagem-marca, Paisagem-matriz: elementos da problemática para uma Geografia Cultural. In: CORRÊA, R. L.; ROZENDAHL, Z. (orgs.). Paisagens, textos e identidade. Rio de Janeiro: EdUERJ, 2004.

CARNEY, G. O. Música e lugar. In: CORRÊA, R. L.; ROSENDAHL, Z. (orgs.). Literatura, música e espaço. Rio de Janeiro: EdUERJ, 2007.

CASSIRER, E. Ensaio sobre o homem: introdução a uma filosofia da cultura humana. São Paulo: Martins Fontes, 1994.

CLAVAL, P. A Geografia Cultural. Florianópolis: EDITORA UFSC, 2001.

COSGROVE, D. A Geografia está em toda parte: cultura e simbolismo nas paisagens humanas. In: CORRÊA, R. L.; ROSENDAHL, Z. (org.). Paisagem, tempo e cultura. Rio de Janeiro: EdUERJ, 1998.

GUI, C. Espaces sonores, lieux et territoires musicaux: les géographes à l'écoute. Cafés Géographiques. oㅜ 1191, 16/11/2007. Disponível em: < http://www.cafegeo.net/article.php3?id_article=1191> Acesso em: 21/01/2008.

HALBWACHS, M. A memória coletiva. São Paulo: Centauro, 2006.

JUNG, C. G. Os arquétipos e o inconsciente coletivo. Petrópolis: Vozes, 2000.

LEVITIN, D. Em busca da mente musical. In: ILARI, B. S. (org.). Em busca da mente musical: ensaios sobre os processos cognitivos em música - da percepção à produção. Curitiba: Ed. da UFPR, 2006. 
LUCHIARI, M. T. D. P. A (re) significação da paisagem no período contemporâneo. In: CORREAA, R. L.; ROSENDAHL, Z. (org.). Paisagem, imaginário e espaço. Rio de Janeiro: EdUERJ, 2001.

MERLEAU-PONTY, M. Fenomenologia da percepção. São Paulo: Martins Fontes, 1999.

PINTO, T. de O. Som e música. Questões de uma antropologia sonora. Revista de Antropologia, São Paulo, v. 44, no 1, p. 222-226, 2001.

POCOCK, D. Sound and the Geographer. Journal of the Geographical Association. № 324, Vol. 74, Part 3. June 1989.

SCHAFER, R. M. A afinação do mundo: uma exploração pioneira pela história passada e pelo atual estado do mais negligenciado aspecto do nosso ambiente: a paisagem sonora. São Paulo: Editora da UNESP, 2001.

1991.

O ouvido pensante. São Paulo: Fundação Editora da UNESP,

SCHIER, R. A. Paisagens e florestas: abordagem histórica e legislação. Curitiba: Reichs Editor, 2004.

TUAN, Y. Topofilia: um estudo da percepção, atitudes e valores do meio ambiente. São Paulo: Difusão Editorial, 1980.

WATERMAN, S. Geography and music: some introductory remarks. GeoJournal, Springer Netherlands, vol. 65, fevereiro 2006.

WISNIK, J. M. O som e o sentido. São Paulo: Companhia das Letras, 1989.

(Recebido em junho/2009. Aceito em dezembro/2009) 